\title{
Adverse Health Effects of Low Dose of Ionizing Radiation among Health Care Workers
}

\author{
By \\ Abbas D ${ }^{1}$, Ez-Elarab HS ${ }^{1}$, Gabal MS ${ }^{1}$, El Khazragy NN ${ }^{2}$ and Manzour AF ${ }^{1}$ \\ ${ }^{1}$ Department of Community, Environmental and Occupational Medicine, ${ }^{2}$ Department of \\ Clinical Pathology, Faculty of Medicine, Ain Shams University, Cairo, Egypt.
}

Corresponding author: Abbas D: dinaabbas@med.asu.edu.eg

\begin{abstract}
Introduction: Ionizing radiation (IR) is an occupational hazard that can induce many biological effects on exposed health care workers (HCWs). However, the health risks of low dose (below $100 \mathrm{mSv}$ ) are controversial due to a lack of direct evidence on human. Aim of work: To identify the adverse health effects of exposure to low dose of ionizing radiation on general health status of health care workers at Ain Shams University hospitals. Materials and methods: A comparative cross-sectional study was conducted including $50 \mathrm{HCWs}$ from different departments of Ain Shams University hospitals: exposed group (exposed to IR for at least I year) $(\mathrm{No}=25)$ and matched unexposed control group $(\mathrm{No}=25)$. Both groups were interviewed using a structured questionnaire. Complete blood count was done for both groups. Recording readings of personal exposure to IR by badge film dosimeter was done after approval from workplace authority. Results: Regarding general health status and wellbeing of workers, most of exposed group had perception of average health status, while most of unexposed group had perception of good health status. Significantly higher sickness absenteeism during the last 6 months was found among the exposed group. A significant adverse health effects, were recorded among exposed compared to control group as hair fall, musculoskeletal pain, pain in upper abdomen, constipation, decreased visual acuity, in addition to be easily agitated. During the last 30 days exposed group had significantly higher frequencies of GIT disturbances and common cold or infections in comparison to unexposed group. Results showed that the Mean Corpuscular Hemoglobin $(\mathrm{MCH})$, absolute lymphocyte and monocyte counts were significantly lower while relative basophils \% was significantly higher among exposed in comparison to unexposed group (although all parameters were within normal range in both groups). Conclusion and recommendations: Chronic exposure to IR -even in small dose- may lead to significant health complains (adverse health effects) and may affect general health status among exposed group compared to the control one. Personal monitoring for ionizing radiation, periodic medical examination, and increasing level of protection for exposed workers are of utmost importance.
\end{abstract}

Keywords: Low dose of ionizing radiation, Healthcare workers, Hematological parameters and Adverse health effects. 


\section{Introduction}

Ionizing radiation (IR) is one of the occupational hazards that can lead to many health hazards on exposed health care workers( $\mathrm{HCWs}$ ) depending on type of IR, level of exposure, dose, dose rates and duration of exposure (Santivasi and Xia, 2014).

It may cause many diseases as cancer, cataract, congenital anomalies, and skin burns. Acute large doses of IR can lead to death shortly after exposure within days or months (Zakora, 2001). In the 19th century, acute exposure to high-dose of IR killed humans and other living organisms. Moreover, it was carcinogenic for survivors exposed to big dose of radiation. So, IR is a dangerous occupational risk that should be used with caution (Vaiserman et al., 2018). However, the health risks of low dose of IR (below 100mSv) are controversial due to a lack of direct evidence on human (Pernot et al., 2012).

The effect of occupational exposure to low levels of IR is an important issue to a large scale of IR exposed workers. Ionizing radiation exposed workers are known to be exposed to chronic and long-term low levels of IR that may have adverse health and immunecompromising effects on their health due to their occupation (Alnahhal et al., 2016).
The biological effects of IR are induced either directly by DNA damaging or indirectly by inducing reactive oxygen species (ROS) which is responsible for the $70 \%$ of all biological effects (Riley et al., 1994; Ahmad et al., 2019), in addition to immunesuppression ( Hayata et al., 2005; Hei et al., 2005).

According to ALARA (As Low As Reasonably Achievable); there is no safe level of radiation even under permissible level as the effects of IR are delayed for years. Those IR effects involve cataract, thyroid disease, cardiovascular changes, cancer and mutagenic effect which may increase risk of genetic diseases in the following generations (ICRP, 2012).

Studies about effects of exposure to low dose of IR among HCWs are lacking. Few studies reported health complains as eye symptoms, headache, repeated infections, and changes in hematological parameters especially differential leukocytic count among exposed health care workers (Saleh et al., 2013 and Alnahhal et al., 2016).

Surveillance of healthcare workers chronically exposed to IR, provides 
information on accidental overexposure, not on the real effect of chronic risk of exposure to low dose of IR which falls below the currently accepted limits (less than 50 millisieverts (mSV) per year) set by International Commission of Radiological Protection (ICRP) (ICRP, 2007; Ahmad et al., 2019). Therefore, there is a strong need to investigate potential adverse effects of exposure to low dose of IR.

\section{Aim of work}

1- To find out the adverse effects of exposure to low dose of ionizing radiation on general health status among health care workers (HCWs) at Ain Shams University hospitals.

2- To compare hematological markers (via complete blood picture) of exposed HCWs versus nonexposed.

\section{Materials and methods}

Study design: A comparative crosssectional study was conducted.

Place and duration of the study: The study was conducted at Ain Shams University hospitals from February to October 2018.
Study Sample: Sample frame was obtained from workers' affairs. Systematic random sampling from frame of HCWS of each group was done.

Sample size: Group sample sizes of 15 HCWs exposed to IR (Ionizing Radiation) and 15 of non-exposed workers achieve $95 \%$ power to detect a difference of 6.9 between the null hypothesis that both group means are 12.5 (mean platelet count as an example for effect of IR on blood parameters (Sayed et al.,2011) and the alternative hypothesis that the mean of group 2 is 5.6 with estimated group standard deviations of 5.5 and 2.6 and with a significance level (alpha) of 0.05 using a two-sided two-sample t-test. Sample was increased to 25 in each group to increase accuracy of results and cover for missing data. The two groups were matched for age and gender (The software used is $\mathrm{G}^{*}$ Power version 3.1.9.2)

\section{Study methods:}

\section{1- Interview questionnaire:}

a- First part: which include personal and occupational histories: age, sex, residence, number of offspring and smoking history and years of employment. 
- Exposure to IR: weekly exposure time, use of PPE (personal protective equipment) and if it is used or not, and causes of non-use, availability of badge film dosimeter.

b- Second part included questions on participants' perception on their general health status (Excellent, Very good, Good, Average and Weak) which were derived from Health status questionnaire (HSQ) (CDC, 2009) and symptoms of low immunity associated with work eg: repeated infections.

c-Third part included health complaints like hair fall, musculoskeletal pain, GIT symptoms, history of any medical illness associated with work.

\section{2- Investigations:}

Blood sample: Two milliliters of venous blood samples were collected into sterile tubes containing ethylene diamine tetra acetic acid (EDTA) from both groups (exposed and unexposed) for complete blood count with deferential leucocytic count.

3- Dosimetry: Recording readings of personal exposure to radiation by dosimetry after approval from workplace authority.

\section{Consent}

An informed consent was taken from each participant and confidentiality of the obtained data was ensured.

\section{Ethical consideration}

Approvals to conduct the study were obtained from Ain Shams University administration and Research Ethics Committee of Faculty of Medicine, Ain Shams University.

\section{Data management}

Data was revised for completeness and consistency, coded entered and analyzed using SPSS version 23 software. Qualitative data were represented as frequency and percent and compared using Chi square. Quantitative data were compared using Student $\mathrm{t}$ test. The level of significance adopted in this study was a two-sided p-value $<0.05$ and the confidence level interval adopted for adjusted odds ratios was $95 \%$.

\section{Results}

The current study was conducted on 50 HCWs, mean age of exposed and unexposed control groups were $34 \pm 7$ and $31 \pm 9.4$ years old respectively. Male HCWs represented $60 \%$ while female represented $40 \%$ of both groups. There were no statistically 
significant differences between both groups regarding socio-demographic characteristics (age, gender, marital status, residence, number of children and smoking history) ( $\mathrm{p}>0.05)$. There were statistically significant differences between both groups regarding units of work and current occupation, as exposed group were recruited from different departments where IR is used as Radio-diagnosis [(conventional (24\%) and interventional (8\%)], Atomic scan (8\%), Cardiac catheterization (20\%) and Collective surgery (vascular, urology, orthopedics, neurosurgery) (40\%). Unexposed group were recruited from inpatient units of Vascular surgery, Urology, Orthopedics and Neurosurgery where IR is not used in those wards. As regards current occupation, most of study participants in both groups (exposed and unexposed) were nurses (48\%, and 68\%) respectively, technicians represented $(32 \%$ and $0 \%$ ), workers (who assist nurses and patients and clean the workplace) represented $12 \%$ of the exposed group and $16 \%$ of the unexposed group meanwhile, physicians represented $8 \%$ of the exposed group and $16 \%$ of the unexposed group. Mean duration of work of HCWs for the exposed and unexposed groups was 12.4+7.9 years and $8+9.1$ years respectively ( $\mathrm{p}$ value $>0.05=0.106, \mathrm{t}=1.64)$. Mean number of working hours per week of HCWs in the exposed and unexposed groups was $47.5+12.8$ hours and $46.8+12$ hours respectively ( $\mathrm{p}$ value $>0.05=0.839$, $\mathrm{t}=0.204)$ (Results are not tabulated).

As regards PPE for protection from IR, $60 \%$ of exposed group did not use leaded aprons while $24 \%$ sometimes did (reason of non-use was due to heaviness in $61.9 \%$ of them while $23.8 \%$ was due to its expiration). Regarding other PPE as (neck apron, protective gloves or glasses), most of the exposed group ( $>90 \%$ ) did not use them due to unavailability. Most of exposed group (64\%) did not receive badge film dosimeter. On the other hand, $16 \%$ out of $36 \%$ of those who receive this badge film did not use it as they ignore their importance. Twenty percent only actually wear this badge film. Badge films were measured every 3 months. Mean badge film measurements reading was $0.58 \pm 0.20 \mathrm{mSv}$ for 3 months exposure (Results are not tabulated). 
Table (1): Frequency of current health problems in relation to radiation exposure among HCWs:

\begin{tabular}{|c|c|c|c|c|c|c|}
\hline Health problems & $\begin{array}{c}\text { Exposed } \\
\mathrm{No}=25\end{array}$ & $\begin{array}{c}\text { Un } \\
\text { exposed } \\
\text { No=25 }\end{array}$ & $\begin{array}{c}\text { Test of } \\
\text { significance }\end{array}$ & p value & $\begin{array}{l}\text { Odds } \\
\text { ratio }\end{array}$ & $95 \%$ CI \\
\hline - Ever had health problem & $21(84 \%)$ & $12(48 \%)$ & $X^{2}=7021$ & $0.007 * *$ & 2.1 & $1.2-3.5$ \\
\hline - Hair fall & $18(72 \%)$ & $9(36 \%)$ & $X^{2}=6.52$ & $0.011 *$ & 2 & $1.1-3.8$ \\
\hline -Musculo-skeletal pain & $18(72 \%)$ & $10(40 \%)$ & $\mathrm{X}^{2}=5.19$ & $0.023 *$ & 1.9 & $1.07-3.3$ \\
\hline -Upper abdominal pain & $13(52 \%)$ & $2(8 \%)$ & $\mathrm{X}^{2}=11.5$ & $0.001 * *$ & 4.9 & $1.3-18.3$ \\
\hline - Constipation & $10(40 \%)$ & $0(0 \%)$ & $\mathrm{X}^{2}=12.5$ & $0.0001 * *$ & - & - \\
\hline - Decrease visual acuity & $6(24 \%)$ & $0(0 \%)$ & $\mathrm{FE}=6.8$ & $0.022 *$ & - & - \\
\hline -Easily agitated & $9(36 \%)$ & $1(4 \%)$ & $\mathrm{FE}=8.00$ & $0.005 * *$ & 6 & $0.9-39$ \\
\hline -Abscess formation & $3(12 \%)$ & $0(0 \%)$ & $\mathrm{FE}=2.19$ & 0.235 & & \\
\hline - Headache & $5(20 \%)$ & $2(8 \%)$ & $\mathrm{FE}=1.49$ & 0.417 & & \\
\hline \multicolumn{3}{|c|}{ *: Statistically significant $(\mathrm{p}<0.05)$} & \multicolumn{4}{|c|}{$* *$ : Highly statistically significant $(\mathrm{p}<0.01)$} \\
\hline \multicolumn{3}{|l|}{$X^{2}=$ chi-square test } & \multicolumn{4}{|c|}{$\mathrm{FE}=$ Fisher's Exact test } \\
\hline
\end{tabular}

By comparing adverse health effects of both groups, the results revealed a statistically significant higher prevalence of some health effects among exposed compared to unexposed groups as regards hair fall ( $\mathrm{p}$ value $=0.011, \mathrm{OR}=2$, $95 \% \mathrm{CI}=1.1-3.8)$, musculoskeletal pain $(\mathrm{p}=0.023, \mathrm{OR}=1.9,95 \% \mathrm{CI}=1.07$ -3.3), upper abdominal pain $(\mathrm{p}=0.001 \mathrm{OR}=4.9,95 \% \mathrm{CI}=1.3-18.3)$, constipation $(\mathrm{p}=0.0001)$, decreased visual acuity $(\mathrm{p}=0.022)$ and easy agitation $(\mathrm{p}=0.005, \mathrm{OR}=$ $6,95 \% \mathrm{CI}=0.9-39)$ which were statistically significantly higher among exposed groupcompared to the control ( $\mathrm{p}$ value $<0.05$ ), while there was no statistically significantdifference between both groups as regard other symptoms (Table 1). 
Table (2): General health status and frequency of health problems during the last 30 days in relation to radiation exposure among HCWs.

\begin{tabular}{|c|c|c|c|c|}
\hline Variables & $\begin{array}{l}\text { Exposed } \\
\text { group } \\
\text { No=25 }\end{array}$ & $\begin{array}{l}\text { Unexposed } \\
\text { group } \\
\text { No=25 }\end{array}$ & $\begin{array}{l}\text { Test of } \\
\text { significance }\end{array}$ & $\mathbf{p}$ \\
\hline $\begin{array}{ll}\text { General health: } \\
-\quad \text { Excellent } \\
-\quad \text { Very good } \\
-\quad \text { Good } \\
-\quad \text { Average } \\
-\quad \text { Weak }\end{array}$ & $\begin{array}{c}0(0 \%) \\
2(8 \%) \\
5(20 \%) \\
16(64 \%) \\
2(8 \%)\end{array}$ & $\begin{array}{c}8(32 \%) \\
1(4 \%) \\
14(56 \%) \\
2(8 \%) \\
0(0 \%)\end{array}$ & $\mathrm{FE}=26.3$ & $0.001 * *$ \\
\hline $\begin{array}{l}\text { Suffer from physical disease as any chronic } \\
\text { or acute diseases or injuries as wounds during } \\
\text { last } 30 \text { days }\end{array}$ & $5(20 \%)$ & $1(4 \%)$ & $\mathrm{FE}=3.03$ & 0.18 \\
\hline $\begin{array}{l}\text { Suffer from mental illness as depression, } \\
\text { stress, problem with emotions }\end{array}$ & $11(44 \%)$ & $5(20 \%)$ & $\mathrm{X}^{2}=3.3$ & 0.069 \\
\hline $\begin{array}{l}\text { Suffer from GIT disturbances as pain in } \\
\text { abdomen, vomiting, diarrhea }\end{array}$ & $14(56 \%)$ & $2(8 \%)$ & $\mathrm{X}^{2}=13.2$ & $0.001 * *$ \\
\hline Suffer from cold or infections & $14(56 \%)$ & $6(24 \%)$ & $\mathrm{X}^{2}=5.3$ & $0.021 *$ \\
\hline Sickness absenteeism during the last 6 months & $8(28 \%)$ & $2(8 \%)$ & $\mathrm{FE}=4.8$ & $0.037 *$ \\
\hline $\begin{array}{l}*: \text { Statistically significant }(\mathrm{p}<0.05) \\
\mathrm{FE}=\text { Fisher's Exact test }\end{array}$ & & $\begin{array}{l}\text { ighly statis } \\
\text { Chi square }\end{array}$ & $\begin{array}{l}\text { ally siq } \\
\text { st. }\end{array}$ & $(\mathrm{p}<0.01)$ \\
\hline
\end{tabular}

By comparing general health status in both groups, it was found that there was statistically significant difference between both groups as regards general health status and immunedeficiency symptoms as most of exposed group (64\%) has average health, while more than half of unexposed group (56\%) has good health. There was a statistically significant difference ( $\mathrm{p}$ value $<0.05$ ) between both groups regarding suffering from GIT disturbances $(\mathrm{OR}=5.4,95 \% \mathrm{CI}=1.4-20.1)$ in last 30 days. Similarly common cold or infections during last 30 days were more among exposed groups with significant difference ( $\mathrm{p}$ value $<0.05$ ) $(\mathrm{OR}=2.1,95 \% \mathrm{CI}=1-4.3)$. Moreover, exposed group have higher frequency of sickness absenteeism in comparison to unexposed group ( $\mathrm{p}$ value $<0.05)(\mathrm{OR}=2.9, \mathrm{CI}=0.8-10.4)$ (Table 2). 
Table (3): Frequency of diseases in relation to radiation exposure among HCWs:

\begin{tabular}{|c|c|c|c|c|}
\hline Variables & $\begin{array}{c}\text { Exposed } \\
\text { No=25 }\end{array}$ & $\begin{array}{c}\text { Unexposed } \\
\text { No=25 }\end{array}$ & $\begin{array}{c}\text { Test of } \\
\text { significance }\end{array}$ & p \\
\hline - One or more Chronic diseases\# & $4(16 \%)$ & $13(52 \%)$ & 7.22 & $\mathbf{0 . 0 0 7 *}$ \\
\cline { 2 - 5 } - $\begin{array}{l}\text { Infertility/ Abortion/ Congenital } \\
\text { malformations in offspring }\end{array}$ & $2(8 \%)$ & $1(4 \%)$ & $\mathrm{FE}=0.35$ & 1.0 \\
\cline { 2 - 5 } & & &
\end{tabular}

*: Statistically significant $(\mathrm{p}<0.05)$

$\mathrm{FE}=$ Fisher's Exact test used

\#: Chronic diseases are (Hypertension, Diabetes, Anemia, liver diseases, Tumors)

By comparing chronic diseases by past history taking for both groups, there was a statistically significant difference between both groups (Table 3).

Table (4): Comparison between studied groups as regards hematological parameters.

\begin{tabular}{|c|c|c|c|c|}
\hline Variables $($ Mean \pm SD) & $\begin{array}{l}\text { Exposed } \\
\text { No }=25\end{array}$ & $\begin{array}{c}\text { Unexposed } \\
\qquad \text { No }=25\end{array}$ & t Test & $p$ value \\
\hline HB & $13.6 \pm 1.8$ & $13.6 \pm 1.83$ & 0.015 & 0.988 \\
\hline - $\quad$ RBCs & $4.7 \pm 0.72$ & $4.5 \pm 0.61$ & 1.01 & 0.17 \\
\hline MCV & $78.1 \pm 7.1$ & $79.7 \pm 6.8$ & 0.807 & 0.424 \\
\hline - $\mathrm{MCH}$ & $29.2 \pm 2.4$ & $31.1 \pm 1.5$ & 3.19 & $0.003 * *$ \\
\hline МCHC & $33.1 \pm 1.4$ & $32.8 \pm 1.06$ & 0.799 & 0.428 \\
\hline HCT & $37 \pm 6.07$ & $34.1 \pm 2.97$ & 2.1 & $0.035 *$ \\
\hline Platelets & $281.2 \pm 81.0$ & $312.6 \pm 74.3$ & 1.42 & 0.160 \\
\hline MPV & $10.4 \pm 1.06$ & $10.03 \pm 1.06$ & 1.31 & 0.198 \\
\hline WBCs & $6595 \pm 2327$ & $8066 \pm 2052$ & 1.77 & 0.08 \\
\hline - $\quad$ Relative Lymphocyte & $36.7 \pm 6.2$ & $37.6 \pm 4.8$ & 0.571 & 0.571 \\
\hline$(\mathrm{LN}) \%$ & & & & \\
\hline Absolute LN & $2.6 \pm 0.96$ & $3.1 \pm 0.81$ & 2.17 & $0.034 *$ \\
\hline Relative Neutrophil \% & $53.2 \pm 6.2$ & $52.3 \pm 4.8$ & 0.581 & 0.564 \\
\hline Absolute Neutrophil & $3.6 \pm 1.3$ & $4.3 \pm 1.2$ & 1.86 & 0.06 \\
\hline Relative Monocyte \% & $8.3 \pm 1.5$ & $8.7 \pm 1.2$ & 1.07 & 0.290 \\
\hline
\end{tabular}




\section{- Absolute Monocyte \\ - $\quad$ Relative Eosinophil \% \\ - Absolute Eosinophil \\ - $\quad$ Relative Basophil \% \\ - Absolute Basophil}

HB: Hemoglobin.

MCV: Mean Corpuscular Volume.

MCHC: Mean Corpuscular Hemoglobin Concentration. WBCs: White Blood Cells.

*: Statistically significant $(\mathrm{p}<0.05)$

\begin{tabular}{c|c|c|c|}
\hline $0.58 \pm 0.25$ & $0.72 \pm 0.21$ & 2.04 & $\mathbf{0 . 0 4 6 *}$ \\
\hline $1.3 \pm 1.4$ & $1.2 \pm 1.27$ & 0.285 & 0.777 \\
\hline $0.08 \pm 0.106$ & $0.11 \pm 0.12$ & 0.822 & 0.415 \\
\hline $0.21+0.23$ & $0.04 \pm 0.08$ & 3.48 & $\mathbf{0 . 0 0 2 *}$ \\
\hline $0.008 \pm 0.013$ & $0.003 \pm 0.007$ & 1.52 & 0.140 \\
\hline
\end{tabular}

\section{HCT: Hematocrit.}

MCH: Mean Corpuscular Hemoglobin. MPV: Mean Platelets Volume.

LN: Lymphocyte

**: Highly statistically significant $(\mathrm{p}<0.01)$

Table 4 showed that there was statistically significant differences between both groups as regards mean of $\mathrm{MCH}$ (which was lower in exposed group $(29.2 \pm 2.4)$ in comparison to unexposed group $(31.1 \pm 1.5)$ with significant level ( $\mathrm{p}$ value $=$ 0.003 ), also absolute lymphocyte and monocyte count were lower among exposed group $(2.6 \pm 0.96,0.58 \pm 0.25)$ respectively in comparison to un exposed group (3.1 $\pm 0.81,0.72 \pm 0.21)$ with significant level ( $\mathrm{p}$ value $=0.034$ and 0.046 ) respectively. As regards relative basophil \%, they were higher among exposed group $(0.21 \pm$ 0.23 ) than unexposed group $(0.04 \pm 0.08)$ with significant level ( $p$ value $=0.002)$ (all hematological parameters were within normal range in both groups including those parameters with statistically significant differences between the studied groups).

\section{Discussion}

Epidemiological and clinical studies about health effects of low dose of IR are poorly considered as there was controversy between studies about the effect of low dose of IR $((\leq 100 \mathrm{mSv})$ (Tang et al., 2018). So, in the present study we try to identify adverse health effects of exposure to low dose of IR on HCWs.
The results of the current work showed that exposed group had significantly higher frequency of some health complains related to work (adverse health effects) as hair fall in comparison to unexposed group (Table 1) and that was in consistent with $\mathrm{WHO}$ report in 2016 and other studies which reported that hair follicles are very sensitive to IR and can be damaged by even low dose rates (WHO, 2016). On 
the other hand, there was disagreement with Dehghani et al., 2014 who declared in their study about effect of low dose of radiation exposure on hair fall among workers that although IR affects hair follicles, but very low dose doesn't have an effect on hair fall. This controversy can be explained by different study population, different working environment, strict regulations of protection and monitoring at workplaces, in addition to differences in dose level of personal exposure between Dehghani et al, 2014 study and our study, as there was no workplace monitoring of IR level at some site as collective surgery and catheterization .

The current study also showed that significantly higher frequency of musculoskeletal pain among exposed group in comparison to unexposed one (Table 1). This was in agreement with Andreassi et al., 2016 who reported in their study on cardiac catheterization laboratory workers who were exposed to IR that the latter had significant higher frequencies of musculoskeletal pain in comparison to control group ( $\mathrm{p}$ value $<0.001$ ). Also there was a statistically significant difference between exposed and control group as regards upper abdominal pain and constipation (Table 1). This is consistent with the study conducted by Saleh et al., 2013 in their study on immunological effects of ionizing radiation among healthcare providers of Nnuclear Medicine Unit at an university hospital, they found higher frequencies of gastritis among exposed workers compared to control group.

The present study showed a statistically significant difference as regards decreased visual acuity among exposed group compared to unexposed one (Table 1) and that was in agreement with Tang et al., 2018 who reported that low dose of IR, may cause eye symptoms as change and decreased vision.

In the current work, exposed group was significantly easily agitated at work in comparison to control group (Table 1). This was in accordance with Pastel, 2002 who detected in his study that low dose of IR exposure may induce long term effect of neuropsychiatric disorders.

As regards general health and immune status (using questionnaire of CDC, 2009), the results of the current study showed that most of the exposed workers had perception of average health in comparison to unexposed group who had perception of good health (Table 2). By asking about 
GIT disturbances as abdominal pain, vomiting, diarrhea in the last 30 days, exposed group have higher frequencies of GIT disturbances with significant difference than control group (Table 2) and that agreed with Saleh et al., 2013 and Alnahhal et al., 2016 and who reported that clinical symptoms such as gastritis, pallor, and anorexia were significantly higher among exposed group compared to control.

Similarly, common cold or repeated infections (symptoms of low immunity) during the last 30 days were significantly more frequent among exposed groups than unexposed group. Moreover, exposed group had significantly higher frequency of sickness absenteeism in comparison to control group (Table 2). This agreed with Alnahhal et al., 2016 in their study on radiation exposure and immunity status of radiographers at government hospitals; who reported the occurrence of a significantly higher percentage of repeated infections among IR exposed workers compared to control group.

There was a significant difference between both groups as regards chronic diseases as diabetes, hypertension, cancer, etc. (Table 3). That was consistent with Andreassi et al., 2016; who found that HCWs exposed to IR had a significantly higher frequency of some chronic diseases like hypertension, orthopedic illness and hypercholesterolemia than unexposed group. On the other hand Vaiserman et al., 2018 declared that low dose of IR may have no effect on occurrence of cancer, cataract or mutagenic effects. Tang et al., 2018 illustrated a controversial opinion in their research; they declared that low dose or low dose rate ionizing radiation may have either negative or positive changes on human body. These changes may depend on genetic background, age, sex, nature of radiation exposure, i.e., acute or chronic irradiation, radiation sources etc. They also concluded that effect of low dose ionizing radiation is poorly understood and needs to be extensively studied.

Complete blood picture (CBC) with differentiated leucocytic count was done for both groups. The results of the current study showed that as regard WBCs and its differentials, absolute lymphocyte and monocyte (which have a crucial role in immunity) were significantly lower among exposed group compared to unexposed, while other differentials of WBCs as neutrophil and others (except relative basophil) were lower among exposed group than unexposed but it didn't reach a significant level. There 
was a statistically significant increase in relative basophil among exposed group in comparison to unexposed (Table 4) (high basophil levels may indicate an autoimmune condition or one of several types of blood disorders, allergy or autoimmune disease). These results (as regards WBCs and lymphocyte) were consistent with the study done by Prabhakara and Lakshman, 2005, who reported in their study a significant decrease in the level of WBCs and lymphocyte among nuclear medicine workers compared to control group.

In contrast to the present study; Al-Saidy, 2014 when he compared exposed technicians with control group showed that there was no change of hematological parameters except in the morphology of lymphocyte.

On the other hand, Alnahhal et al., 2016 found in their study that regarding WBCs and its differentials, the results did not show statistically significant differences in all parameters between exposed and control groups. This discrepancy may be due to the different occupational workplaces with different IR exposure level in those studies.

As regards RBCs and $\mathrm{HB}$ concentration levels, they were nearly the same in both groups, the difference were in $\mathrm{MCH}$ (which is an indicator of iron stores ) which was significantly lower among exposed group compared to unexposed and hematocrit value(which indicates percentage volume of RBCs which is higher among exposed group compared to unexposed group). Many studies showed no differences in all RBCs parameters among radiation workers (RBCs, HB, MCH, MCHC, MCV, Hematocrit) (Zakeri et al., 2010; Shahid et al., 2014 and Alnahhal et al., 2016). On the other hand, Doukali et al., 2016 in their study on 29 Tunisian medical staff from radiology and radiotherapy departments compared to control showed that, a significant decrease by $11 \%$ of $\mathrm{Hb}(\mathrm{p}<0.01)$ were noted among exposed subjects.

Similarly, Puthran et al., 2009 in their study revealed that there was a significant increase in the susceptibility of RBCs to hemolysis in radiation exposed workers compared to controls. This discrepancy may refer to different dose rate of exposure at different workplaces with different strict regulation. Although the biological effects of high levels of IR exposure on hematological parameters are well known, but the effects of low levels of IR are more difficult to determine because the deterministic effects may not occur at these levels. So, the 
effect of low dose IR on hematological parameters is controversial and showed high discrepancy between different studies. Further studies are needed with larger sample size on this topic.

\section{Conclusion:}

The present study revealed that chronic exposure to low doses of ionizing radiation (IR) cause many health complaints as hair fall, musculoskeletal pain, upper abdominal pain, constipation, decreased visual acuity and easily agitated in comparison to unexposed group. Moreover, chronic exposure to low doses of IR affects general health status and immune system, significant clinical symptoms related to the immunity troubles as (repeated infections, common cold and GIT disturbances) have been reported on exposed workers. Significant change effect of some basic blood parameters as absolute lymphocyte, monocyte, relative basophil, $\mathrm{MCH}$ and hematocrit among IR exposed workers were evident (although all hematological parameters were within normal range).

\section{Recommendations:}

According to the results of the study, the following can be recommended:

Personnel monitoring for ionizing radiation and providing personal protective equipment for the exposed workers is of utmost importance. Health education for all workers who are exposed to IR which should focus on health hazards of IR, frequent safety training courses should be provided for all HCW and auditing of work practices to avoid possible adverse effects of IR , life style changes which may mitigate the potentially harmful effect of IR. Further studies are needed on the effect of low dose IR among exposed health care workers as only few studies were available in that topic.

\section{Conflict of interest}

The authors declared that they have no competing of interest.

\section{Funding}

None

\section{References}

1. Ahmad MI, Maher YA, Tiffany MA, Lisa B, Adam GC et al. (2019): Healthcare Workers Occupationally Exposed to Ionizing Radiation Exhibit Altered Levels of Inflammatory Cytokines and Redox Parameters. Antioxidants (Basel); 8(1): 12.

2. Ahmad IM, Temme JB, Abdalla MY and Zimmerman MC (2016): Redox status in workers occupationally exposed to longterm low levels of ionizing radiation: A pilot study. Redox Rep; 21: 139-45. 
3. Alnahhal M, Alajerami YS, Jaber S, Abushab K and Najim A (2016): Radiation exposure and immunity status of radiographers at government hospitals. Original research. International Journal of Medical Science and Public Health; 6(2): 232- 8 .

4. Al-Saidy A (2014): Effects of Radiation on the Hematological Parameters in X-Ray Technicians: A Case-Control Study. Research Gate; 4 (2):85-8.

5. Andreassi GM, Piccaluga E, Guagliumi G, Greco M and Picano E (2016): Occupational Health Risks in Cardiac Catheterization Laboratory Workers. Circulation: Cardiovascular Interventions; 9(4):e003273. doi: 10.1161 CIRCINTERVENTIONS.115.003273.

6. Cardis E, Vrijheid M, Blettner M, Gilbert E, Hakama M, et al. (2005): Risk of cancer after low doses of ionizing radiation: retrospective cohort study in 15 countries". BMJ; 331(7508): 77.

7. Centers for Disease Control and Prevention (CDC) (2009): National Health and Nutrition Examination Survey (NHANES). Current health status -Health survey questionnaire HSQ .Available at: (https://wwwn.cdc.gov/nchs/data/ nhanes/2009-2010/questionnaires/mi_ hsq_f.pdf).
8. Dehghani S, Mofid B, Momeni $\mathrm{H}$ and Ahmadi S (2014): The roles of chronic exposure on hair fall in radiation workers. Res Med; 37 (4):228-31.

9. Doukhali H, salah G, Hamdaoui L and Mounira H D (2017): Oxidative stress and GSTs genetic polymorphisms in medical staff professionally exposed to ionizing radiation. Int J Radiat Biol; 93(7):1-25.

10. Hayata I (2005): Chromosomal mutations by low dose radiation vs. those by other mutagenic factors. Int Congr Ser; 1276:1720.

11. Hei TK, Zhou H and Suzuki M (2005): Extranuclear target and low dose radiation risk assessment. Int Congr Ser; 1276: 21-4.

12. International Commission of Radiation Protection (ICRP) (2007): The 2007 Recommendations of the International Commission on Radiological Protection. ICRP publication 103. Ann ICRP; 37:1332.

13. International Commission of Radiation Protection (ICRP) (2012): Early and late effects of radiation in normal tissues and organs: Threshold doses for tissue reactions and other non-cancer effects of radiation in a radiation protection context. ICRP Publication 118. Ann. ICRP 41(1/2). Available at: http://www.icrp.org (accessed on $22 / 3 / 2017$ ) 
14. Pastel RH (2002): Radiophobia: long-term psychological consequences of Chernobyl. Mil Med; 167:134-6.

15. Pernot E, Hall J, Baatout S, Benotmane MA, Blanchardon E et al. (2012): Ionizing radiation biomarkers for potential use in epidemiological studies. Mutat Res; 751(2):258-86.

16. Prabhakara M and Lakshman KV (2005): Assessment of risk at workplace: a study on radiographers work practices in Vizag Steel. Ind J Occup Environ Med; 9(1): 26-8.

17. Puthran SS1, Sudha K, Rao GM and Shetty BV (2009): Oxidative stress and low dose ionizing radiation. Indian J Physiol Pharmacol; 53(2):181-4.

18. Riley PA (1994): Free radicals in biology: Oxidative stress and the effects of ionizing radiation. Int J Radiat Biol ; 65: 27-33.

19. Saleh M, Zayet H, Ez-Aldin A, Mohammed W, Thabet A, et al. (2013): Immunological effects of ionizing radiation among healthcare providers of nuclear medicine unit at university hospital. Egyptian J Comm Med; 31(4): 66-78.

20. Sayed D, Abd Elwanis M, Abd Elhameed $S$ and Galal H (2011): Does occupational exposure to low-dose ionizing radiation affect bone marrow thrombopoiesis? Int Arch Med 4:8 doi:10.1186/1755-7682-4-8

21. Santivasi WL and Xia F (2014): Ionizing radiation-induced DNA damage, response, and repair. Antioxid Redox Signal; 21(2):251-9.

22. Shahid S, Mahmoud N, Chaudhry M, Shaikh S and Ahmad N (2014): Assessment of impacts of hematological parameters of chronic ionizing radiation exposed workers in hospitals. Fuuast J Bio; 4(2): 135-46.

23. Tang FR and Loganovsky K 2018: Low dose or low dose rate ionizing radiationinduced health effect in the human. J Environ Radioact; 192:32-47.

24. Vaiserman A, Koliada A, Zabuga O and Socol Y (2018): Health Impacts of LowDose Ionizing Radiation: Current Scientific Debates and Regulatory Issues. Dose Response; 16(3): 1559325818796331. doi: $10.1177 / 1559325818796331$.

25. World Health Organization (WHO) (2016): Ionizing radiation, health effects and protective measures, fact sheet. Available at: https:/www.who.int/news-room/factsheets/detail/ionizing-radiation-healtheffects-and-protective-measures.

26. Zakeri F, Hirobe T and Noghabi K (2010): Biological effects of low dose ionizing radiation on interventional cardiologists. Occup Med J; 60: 464-9.

27. Zakora M (2001): Occupational exposure in angiography. J Radiation Prot Dosimetry; 94 (1):129-32. 
